\title{
Associations between apolipoprotein E gene polymorphisms and Alzheimer's disease risk in a large Chinese Han population
}

This article was published in the following Dove Press journal:

Clinical Interventions in Aging

30 January 2015

Number of times this article has been viewed

\author{
Ping $\mathrm{Wu}^{1,2}$ \\ Hong-Lei $\mathrm{Li}^{\prime}$ \\ Zhi-Jun Liu' \\ Qing-Qing Tao' \\ Miao $\mathrm{Xu}^{\prime}$ \\ Qi-Hao Guo' \\ Zhen Hong' \\ Yi-Min Sun'
}

'Department of Neurology and Institute of Neurology, ${ }^{2}$ PET

Center, Department of Nuclear

Medicine, Huashan Hospital, Shanghai

Medical College, Fudan University,

Shanghai, People's Republic of China
Correspondence: Yi-Min Sun

Department of Neurology and Institute of Neurology, Huashan Hospital, Shanghai Medical College, Fudan University, 12 Wulumuqi Zhong Road, Shanghai 200040, People's Republic of China

$\mathrm{Tel} / \mathrm{Fax}+862162483421$

Email ys2504@sina.com
Objective: Apolipoprotein E gene ( $A P O E$ ) polymorphisms contributing to the risk of sporadic Alzheimer's disease (AD) have been identified for decades, but it has not been investigated in large AD samples of Chinese Han population.

Methods: We performed a cross-sectional study to explore the effect of APOE polymorphisms on sporadic AD in 875 sporadic $\mathrm{AD}$ patients and 1,195 cognitive normal controls of Chinese Han. Genotyping of $A P O E$ was determined by multiplex amplification refractory mutation system polymerase chain reaction.

Results: $A P O E \varepsilon 3 \varepsilon 4$ and $\varepsilon 4 \varepsilon 4$ genotypes increased AD risk with dosage effect. The odds ratio (OR) of $\varepsilon 3 \varepsilon 4$ was 1.89 and the OR of $\varepsilon 4 \varepsilon 4$ was 15.64 compared with that of $\varepsilon 3 \varepsilon 3$ in all the subjects. $E 2 \varepsilon 3$ genotype decreased $A D$ risk in all the subjects $(\mathrm{OR}=0.64)$, female subgroup $(\mathrm{OR}=0.57)$, and late-onset $\mathrm{AD}$ subgroup $(\mathrm{OR}=0.60)$. However, neither $\varepsilon 2 \varepsilon 2$ nor $\varepsilon 2 \varepsilon 4$ affected $\mathrm{AD}$ risk. About the age at onset (AAO), the influence of $A P O E \varepsilon 4$ was only exhibited in late-onset $\mathrm{AD}$ subgroup, with 1 year lower in $\varepsilon 4$-positive ones than negative ones. Further analysis did not show the dosage effect of $\varepsilon 4$ pertinent to AAO, though the AAO of $\varepsilon 4 \varepsilon 4$ patients decreased by 2 years. $E 2$ did not affect the AAO of AD.

Conclusion: $A P O E \varepsilon 4$ is a strong risk factor of $\mathrm{AD}$ risk in Chinese Han population, and $A P O E$ $\varepsilon 4 \varepsilon 4$ genotype might be related to the AAO of late-onset AD.

Keywords: sporadic, cross sectional study, dosage effect, age at onset

\section{Introduction}

Alzheimer's disease (AD) is the most common cause of senile dementia characterized by progressive decline in cognition and behaviors. The cause of AD was complex, and genetic factors contributed to its risk. Mutations on three genes of amyloid precursor protein, presenilin 1, and presenilin 2 are associated with rare familial early-onset $\mathrm{AD}(\mathrm{EOAD})$. As for the majority of sporadic $\mathrm{AD}$ (SAD), apolipoprotein $\mathrm{E}$ gene $(A P O E)$ was the only one confirmed to be related with SAD risks since 1993, ${ }^{1,2}$ and the results were replicated by many candidate genetic studies in different populations and different regions all around the world. ${ }^{3}$ Recent genome-wide association studies found that $A P O E$ is far more significantly related to AD risk than all the other candidate loci. ${ }^{4,5}$

The APOE gene located in 19q13.2, encoding apoE, which consists of 299 amino acids, is a cholesterol carrier involved in lipid transportation and injury repair in the brain. $A P O E$ has three common isoforms termed $\varepsilon 2, \varepsilon 3$, and $\varepsilon 4$, which could be determined by cysteine-arginine substitutions at residues 112 and 158 . The frequencies of these three alleles are different among ethnics. ${ }^{6}$ Generally, $\varepsilon 3$ is the most common allele, accounting for $60 \%-90 \%$ of the allelic variation. The 
$\varepsilon 2$ constitutes $0 \%-20 \%$ of allelic variation and $\varepsilon 4$ constitutes 10\%-20\% (http://asia.ensembl.org/Homo sapiens/ Variation/Population). The $\varepsilon 4$ was proved to increase AD risk in a dose-dependent pattern and lower the age at disease onset compared with $\varepsilon 4$ noncarriers. ${ }^{7}$ It was also reported as a risk factor for the conversion of mild cognitive impairment to $\mathrm{AD} .{ }^{8}$ In contrast, $\varepsilon 2$ was reported to have a "protective" effect on $\mathrm{AD}$ risk and to slower cognitive function decline than $\varepsilon 2$-negative status. ${ }^{9}$

The association between APOE polymorphisms and $\mathrm{AD}$ risk has been investigated in Caucasian, Hispanic, African American, Japanese, and small numbers of Chinese Han populations. ${ }^{10-12}$ Other studies of candidate genes and AD risk in Chinese Han population used $A P O E$ E4-carrying status as a stratification sign but did not focus on $A P O E$ itself. ${ }^{13}$ Here we investigated a large number of $875 \mathrm{SAD}$ and 1,195 controls of Chinese Han to explore the association between APOE polymorphisms and $\mathrm{AD}$ risk.

\section{Materials and methods Subjects}

A total of 875 SAD patients and 1,195 unrelated healthy controls were included in this cross-sectional study. All the subjects were from Chinese Han population. SAD patients were recruited from memory disorders clinics in Huashan Hospital between March 2007 and September 2013 with a median age of 72 years (range 48-100 years). Cognitively normal controls with age, sex, and origins similar to SAD patients were recruited from the community epidemiologic investigations (median age of 69 years, range 48-94 years). The enrollment procedure and the inclusion and exclusion criteria for SAD cases and controls were as previously reported. ${ }^{14}$ The diagnosis of $\mathrm{AD}$ was according to the criteria of Diagnostic and Statistical Manual of Mental Disorders IV revised. Written consents were obtained from subjects or their legally authorized caregivers. This study was approved by the ethics committee of Huashan Hospital.

\section{Genotyping of $A P O E$}

Genomic DNA was extracted from peripheral blood using a Blood Genomic DNA Extraction Kit (TIANGEN, Shanghai, People's Republic of China). The APOE genotypes were determined by multiplex amplification refractory mutation system polymerase chain reaction according to the method previously described. ${ }^{15}$

\section{Statistical analysis}

Hardy-Weinberg equilibrium tests of $A P O E$ polymorphisms within the groups were performed using $\chi^{2}$ analysis. The $\chi^{2}$ test or Student's $t$-test was used to test for the differences between $\mathrm{AD}$ and control subjects in the distribution of sex, age at onset (AAO), and mini-mental state examination scores. The $\chi^{2}$ test was used to compare the genotypes and allele frequencies between $\mathrm{AD}$ patients and control subjects. Odds ratio (OR) and the 95\% confidence interval (CI) for testing possible associations between $\mathrm{AD}$ and control groups were determined by binary logistic regression analyses; AAO and sex were used as covariates. The potential effects of each genotype on AAO in AD patients were calculated by one-way analysis of variance and further analysis by post hoc least significant difference. All statistical analyses were performed using SPSS version 13.0 (SPSS Inc, Chicago, IL, USA). $P<0.05$ was considered significant.

\section{Results \\ General information}

General information of the participants is shown in Table 1. No significant difference was found in age and sex between the two groups, while the mini-mental state examination score was significantly lower in $\mathrm{AD}$. The distributions of the six common genotypes of $A P O E$ were under Hardy-Weinberg equilibrium in SAD patients and control subjects, respectively (Table S1).

\section{$\varepsilon 2$ allele decreased $A D$ risk and $\varepsilon 4$ allele increased $A D$ risk}

In all the subjects, the distribution of allele frequencies and genotypes of $A P O E$ was of significant difference between

Table I Characteristics of subjects in AD and control groups

\begin{tabular}{llll}
\hline & AD & Control & $P$ \\
\hline Number & 875 & 1,195 & \\
Agea (mean \pm SD) (range), years & $67.7 \pm 9.67(45-97)$ & $68.5 \pm 10.13(48-94)$ & 0.106 \\
Male/female & $397 / 478$ & $493 / 702$ & 0.062 \\
MMSE (mean \pm SD) & $14.3 \pm 6.35$ & $28.6 \pm 1.85$ & $0.000^{*}$ \\
\hline
\end{tabular}

Notes: $* P<0.01$. age at onset for $A D$; age at entrance for control.

Abbreviations: AD, Alzheimer's disease; MMSE, mini-mental state examination; SD, standard deviation. 
$\mathrm{AD}$ and control groups with more $\varepsilon 2, \varepsilon 3$ allele and less $\varepsilon 4$ allele in controls (Table 2). There were also more $\varepsilon 2$-carrying subjects ( $\varepsilon 2 \varepsilon 2, \varepsilon 2 \varepsilon 3$, and $\varepsilon 2 \varepsilon 4$ ) and less $\varepsilon 4$-carrying subjects $(\varepsilon 2 \varepsilon 4, \varepsilon 3 \varepsilon 4, \varepsilon 4 \varepsilon 4)$ in the control group than in the $\mathrm{AD}$ group. When the subjects were further stratified by sex and AAO (AD with $\mathrm{AAO} \leq 65$ was defined as $\mathrm{EOAD}$; $\mathrm{AAO}>65$ as late-onset $\mathrm{AD}[\mathrm{LOAD}])$, the differences remained significant (Table 2).

The impact of $A P O E$ genotype and allele frequencies on SAD risks was analyzed by binary logistic regression. As shown in Table 3, in all the subjects, $\varepsilon 2 \varepsilon 3$ genotype decreased AD risk $\left(P=8 \times 10^{-3}\right.$, OR $0.64,95 \%$ CI $\left.0.46-0.89\right)$ while $\varepsilon 2 \varepsilon 2$ and $\varepsilon 2 \varepsilon 4$ genotypes did not statistically relate to $\mathrm{AD}$ risk. On the contrary, $\varepsilon 3 \varepsilon 4$ and $\varepsilon 4 \varepsilon 4$ genotype increased AD risk with dosage effect of $\varepsilon 4$ : the OR of $\varepsilon 3 \varepsilon 4$ was 1.90 $\left(P=1.18 \times 10^{-9}, 95 \%\right.$ CI 1.54-2.33) while the OR of $\varepsilon 4 \varepsilon 4$ rose to $15.64\left(P=8.59 \times 10^{-15}, 95 \%\right.$ CI $\left.7.92-32.05\right)$. When the subjects were further divided by sex and AAO, the $\varepsilon 4$ dosage effect remained constant, but the protective effect of $\varepsilon 2 \varepsilon 3$ was significant only in the female subgroup and LOAD subgroup. As for the $\varepsilon 2$ - and $\varepsilon 4$-carrying status, $\varepsilon 2$ allele lowered the risk of developing $\mathrm{AD}$ while $\varepsilon 4$ increased this risk, which existed in all subgroups after the subjects were stratified by sex and AAO, with the highest OR of 2.79 in female $\varepsilon 4$-positive subjects (Table 3).

\section{APOE $\varepsilon 4 \varepsilon 4$ may be associated with an earlier AAO in LOAD patients}

In $\mathrm{AD}$ patients, only in LOAD was the AAO found to be significantly lower in $\varepsilon 4$ allele-positive subjects than $\varepsilon 4$ allele-negative ones $\left(73.9 \pm 5.12\right.$ vs $\left.74.9 \pm 5.18, P=2.2 \times 10^{-2}\right)$ (Table 4). Nevertheless, there was no difference in AAO between the $\varepsilon 2$-positive $\mathrm{AD}$ and $\varepsilon 2$-negative ones. We further investigated the $\mathrm{AAO}$ according to the dosage of $\varepsilon 2$ and $\varepsilon 4$. The AAO was 2 years lower in patients of $\varepsilon 4 \varepsilon 4$ genotype than $\varepsilon 4$ carriers ( $\varepsilon 2 \varepsilon 4$ and $\varepsilon 3 \varepsilon 4$ ) or $\varepsilon 4$-negative ones. But no dosage effect of $\varepsilon 4$ on AAO was found.

We further investigated the effect of $A P O E \varepsilon 2$ and $\varepsilon 4$ haplotype on $\mathrm{AD}$ risk in different $\mathrm{AAO}$ and found $\varepsilon 2$ 's protective role against $\mathrm{AD}$ in the patients with $\mathrm{AAO}$ of $61-65$ and above 76 (Table 5). The $\varepsilon 4$ haplotype increased AD risk in patients with AAO below 55 and $61-75$ with the highest OR of 3.842 in 66-70 groups. The risk decreased when AAO was above 76 , though there was no significant difference.

\section{Discussion}

In 1993, APOE $\& 4$ was first reported to increase SAD risks and advance $\mathrm{AAO}$ of $\mathrm{AD}$ in a gene dosage way. ${ }^{1,2,16}$ Except

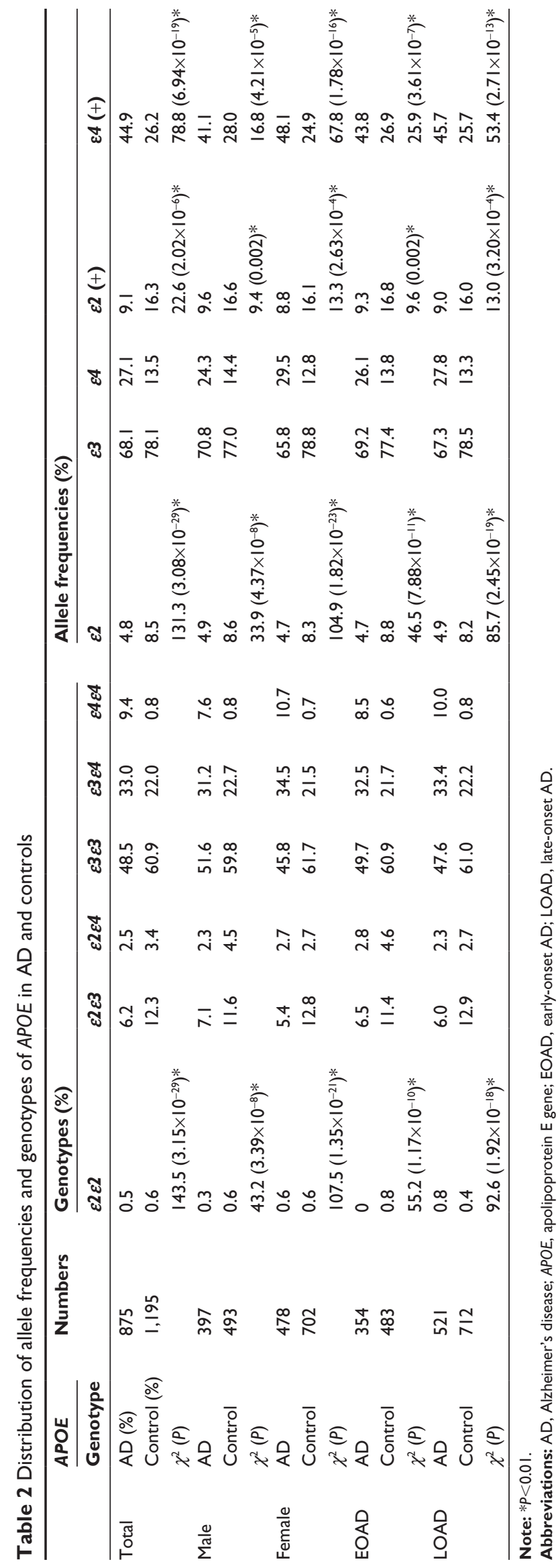


Table 3 Logistic regression of APOE genotypes and allele frequencies in Alzheimer's disease patients and controls

\begin{tabular}{|c|c|c|c|c|c|c|c|c|}
\hline Total & $\varepsilon 2 \varepsilon 2$ & $\varepsilon 2 \varepsilon 3$ & $\varepsilon 2 \varepsilon 4$ & $\varepsilon 3 \varepsilon 3$ & $\varepsilon 3 \varepsilon 4$ & $\varepsilon 4 \varepsilon 4$ & $\varepsilon 2(+)$ & $\varepsilon 4(+)$ \\
\hline$P$ & 0.994 & $8 \times 10^{-3 *}$ & 0.682 & I.ref & $1.18 \times 10^{-9 *}$ & $8.59 \times 10^{-15 *}$ & $2.88 \times 10^{-6 *}$ & $1.57 \times 10^{-18 *}$ \\
\hline OR & 1.01 & 0.64 & 0.90 & & 1.90 & 15.93 & 0.52 & 2.30 \\
\hline $95 \% \mathrm{Cl}$ & $0.29-3.46$ & $0.46-0.89$ & $0.53-1.53$ & & $1.54-2.33$ & $7.92-32.05$ & $0.39-0.68$ & $1.91-2.77$ \\
\hline \multicolumn{9}{|l|}{ Male } \\
\hline$P$ & 0.50 & 0.22 & 0.16 & I.ref & $4 \times 10^{-3 *}$ & $8.87 \times 10^{-6 *}$ & $6 \times 10^{-3 *}$ & $7.22 \times 10^{-5 *}$ \\
\hline OR & 0.46 & 0.735 & $0.56 \mathrm{I}$ & & 1.58 & 11.06 & 0.54 & 1.77 \\
\hline $95 \% \mathrm{Cl}$ & $0.05-4.42$ & $0.45-1.20$ & $0.25-1.25$ & & $1.16-2.16$ & $3.83-31.94$ & $0.36-0.81$ & I.34-2.34 \\
\hline \multicolumn{9}{|l|}{ Female } \\
\hline$P$ & 0.61 & $1.8 \times 10^{-2 *}$ & $0.4 I$ & I.ref & $3.79 \times 10^{-8 *}$ & $2.02 \times 10^{-10 *}$ & $3.19 \times 10^{-4 *}$ & $4.61 \times 10^{-16 *}$ \\
\hline OR & 1.48 & 0.57 & 1.36 & & 2.16 & 20.58 & 0.50 & 2.79 \\
\hline $95 \% \mathrm{Cl}$ & $0.33-6.66$ & $0.36-0.91$ & $0.66-2.80$ & & I.64-2.84 & $8.10-52.27$ & $0.35-0.73$ & $2.18-3.58$ \\
\hline \multicolumn{9}{|l|}{ EOAD } \\
\hline$P$ & 1.00 & 0.25 & 0.45 & I.ref & $4.17 \times 10^{-4 *}$ & $1.91 \times 10^{-6 *}$ & $3 \times 10^{-3 *}$ & $6.73 \times 10^{-7 *}$ \\
\hline OR & 0.00 & 0.74 & 0.74 & & 1.80 & 18.83 & 0.52 & 2.10 \\
\hline $95 \% \mathrm{Cl}$ & 0 & $0.44-1.24$ & $0.34-1.61$ & & I.30-2.50 & $5.63-63.03$ & $0.34-0.80$ & $|.57-2.8|$ \\
\hline \multicolumn{9}{|l|}{ LOAD } \\
\hline$P$ & 0.28 & $2.3 \times 10^{-2 *}$ & 0.82 & I.ref & $1.18 \times 10^{-6 *}$ & $1.25 \times 10^{-9 *}$ & $1.0 \times 10^{-3 *}$ & $9.73 \times 10^{-13 *}$ \\
\hline OR & 2.30 & 0.60 & 1.09 & & 1.94 & $|4.4|$ & 0.53 & 2.41 \\
\hline $95 \% \mathrm{Cl}$ & $0.5 I-10.4 I$ & $0.39-0.93$ & $0.52-2.28$ & & I.48-2.53 & $6.09-34.08$ & $0.37-0.76$ & $1.89-3.07$ \\
\hline
\end{tabular}

Note: $* p<0.01$.

Abbreviations: APOE, apolipoprotein E gene; Cl, confidence interval; EOAD, early-onset Alzheimer's disease; LOAD, late-onset Alzheimer's disease; OR, odds ratio.

for several investigations, ${ }^{17}$ most studies confirmed the results. ${ }^{18-23}$ The dose effect of APOE $\varepsilon 4$ on AD risk was reported to be ascribed to increased $A \beta, A \beta$ oligomers, and plaque deposition and reduced metabolism in certain parts of the brain. ${ }^{24}$

The allele frequencies and genotypes vary among different ethnic groups. ${ }^{25}$ In our study, the $A P O E$ allele frequencies (AD: $\varepsilon 24.8 \%, \varepsilon 368.1 \%$, and $\varepsilon 427.1 \%$; control $\varepsilon 28.5 \%$, $\varepsilon 378.1 \%$, and $\varepsilon 413.5 \%$ ) were similar to the $A P O E$ survey in Shanghai consisting of $65 \mathrm{AD}$ patients and 363 cognitively normal controls (AD: $\varepsilon 24.6 \%, \varepsilon 370 \%$, and $\varepsilon 425.4 \%$; control: $\varepsilon 28.6 \%, \varepsilon 380.4 \%$, and $\varepsilon 411 \%){ }^{6}$ We also found that the $A P O E \& 4$ was the independent risk factor of $\mathrm{AD}$ and increased the $\mathrm{AD}$ risk in a gene dosage way. This is quite consistent with the investigations in other populations. ${ }^{7,26,27}$ However, the ORs in $\varepsilon 3 \varepsilon 4$ genotype toward AD risks were relatively smaller in all the subjects and subgroups of LOAD, EOAD, male, and female (1.579-2.159) groups, compared with those reported in other studies ${ }^{7,21,25,28}$ (usually $>2$ ). The ORs in $\varepsilon 4 \varepsilon 4$ genotype ranged from 11.061 to 20.581 , much greater than those of $\varepsilon 3 \varepsilon 4$ and in accordance with the results in other studies. The genotype of $\varepsilon 2 \varepsilon 4$ showed a risk factor of $\mathrm{AD}$ in some studies, ${ }^{7}$ but did not show any protective or risk effect on $\mathrm{AD}$ pathogenesis in our study, which might

Table 4 The APOE $\varepsilon 2$ and $\varepsilon 4$ allele dosage effect on age at onset in AD patients

\begin{tabular}{|c|c|c|c|c|c|c|c|c|c|c|}
\hline & $\varepsilon 2(+)$ & & $\varepsilon 2(-)$ & & No $\varepsilon 2$ & & One $\varepsilon 2$ & & Two $\varepsilon 2$ & \\
\hline Total AAO, n & $67.7 \pm 9.60$ & 80 & $67.7 \pm 9.69$ & 795 & $67.7 \pm 9.69$ & 795 & $67.5 \pm 9.75$ & 76 & $72.0 \pm 4.97$ & 4 \\
\hline EOAD AAO, n & $57.9 \pm 4.30$ & 33 & $57.7 \pm 5.09$ & 321 & $57.7 \pm 5.01$ & 321 & $57.9 \pm 4.30$ & 33 & 0 & 0 \\
\hline LOAD AAO, n & $74.6 \pm 5.30$ & 47 & $74.4 \pm 5.17$ & 474 & $74.4 \pm 5.17$ & 474 & $74.9 \pm 5.32$ & 43 & $72.0 \pm 4.97$ & 4 \\
\hline Male AAO, n & $67.0 \pm 9.24$ & 38 & $67.6 \pm 9.77$ & 359 & $67.6 \pm 9.77$ & 359 & $66.7 \pm 9.18$ & 37 & 78.0 & $\mathrm{I}$ \\
\hline \multirow[t]{2}{*}{ Female AAO, $n$} & $68.4 \pm 9.98$ & 42 & $67.8 \pm 9.63$ & 436 & $67.8 \pm 9.62$ & 436 & $68.3 \pm 10.32$ & 39 & $70.0 \pm 9.64$ & 3 \\
\hline & $\varepsilon 4(+)$ & & $\varepsilon 4(-)$ & & No $\varepsilon 4$ & & One $\varepsilon 4$ & & Two $\varepsilon 4$ & \\
\hline Total AAO, n & $67.9 \pm 9.80$ & 706 & $68.2 \pm 10.01$ & $\mathrm{I}, 364$ & $67.8 \pm 9.95$ & 482 & $67.6 \pm 9.69$ & 311 & $67.4 \pm 7.88$ & 82 \\
\hline EOAD AAO, n & $58.0 \pm 5.13$ & 155 & $57.6 \pm 4.93$ & 199 & $57.6 \pm 4.93$ & 199 & $57.6 \pm 5.20$ & 125 & $59.2 \pm 4.72$ & 30 \\
\hline LOAD AAO, n & $73.9 \pm 5.12$ & 238 & $74.9 \pm 5.18^{\mathrm{a}}$ & 283 & $74.9 \pm 5.18$ & 283 & $74.4 \pm 5.10$ & 186 & $72.2 \pm 4.86^{b}$ & 52 \\
\hline Male AAO, n & $67.8 \pm 9.58$ & 163 & $67.3 \pm 9.82$ & 234 & $67.3 \pm 9.81$ & 234 & $67.6 \pm 9.85$ & 133 & $68.6 \pm 8.38$ & 30 \\
\hline Female AAO, $n$ & $67.5 \pm 9.17$ & 230 & $68.2 \pm 10.08$ & 248 & $68.2 \pm 10.08$ & 248 & $67.7 \pm 9.59$ & 178 & $66.7 \pm 7.57$ & 52 \\
\hline
\end{tabular}

Notes: ${ }^{a}$ Difference between AAO in LOAD in $\varepsilon 4(+)$ and $\varepsilon 4(-)$ status was significant $(P=0.022)$. ${ }^{\mathrm{b}} \mathrm{Difference}$ between $\mathrm{AAO}$ in LOAD in carriers of one and two APOE 4 alleles was significant $(P=0.006)$.

Abbreviations: AD, Alzheimer's disease; AAO, age at onset; APOE, apolipoprotein E gene; EOAD, early-onset AD; LOAD, late-onset AD. 
Table 5 Effect of APOE $\varepsilon 2$ and $\varepsilon 4$ haplotype on AD risk stratified by age

\begin{tabular}{llllll}
\hline & AAO & AD (\%) & Control (\%) & P-value & OR (95\% CI) \\
\hline$\varepsilon 2(+)$ & $\leq 55$ & $9(8.0)$ & $26(15.8)$ & 0.088 & $0.492(0.218-1.110)$ \\
& $56-60$ & $15(11.7)$ & $20(15.2)$ & 0.572 & $0.810(0.391-1.680)$ \\
& $61-65$ & $9(7.9)$ & $35(18.8)$ & $0.016 *$ & $0.382(0.175-0.833)$ \\
& $66-70$ & $13(10.0)$ & $20(12.9)$ & 0.422 & $0.737(0.349-1.554)$ \\
& $71-75$ & $16(8.7)$ & $6(14.6)$ & 0.062 & $0.552(0.296-1.030)$ \\
& $76-80$ & $11(7.9)$ & $31(18.6)$ & $0.009 * *$ & $0.376(0.181-0.781)$ \\
& $>80$ & $7(10.3)$ & $27(18.9)$ & $0.027 *$ & $0.888(0.800-0.986)$ \\
& $\leq 55$ & $51(45.5)$ & $49(29.7)$ & $0.010^{*}$ & $1.954(1.173-3.256)$ \\
& $56-60$ & $49(38.3)$ & $35(26.5)$ & 0.051 & $1.700(0.998-2.896)$ \\
& $61-65$ & $55(48.2)$ & $46(24.7)$ & $5.13 \times 10^{-5 * *}$ & $2.817(1.706-4.650)$ \\
& $66-70$ & $73(56.2)$ & $39(25.2)$ & $1.59 \times 10^{-7 * *}$ & $3.842(2.323-6.355)$ \\
& $71-75$ & $84(45.7)$ & $54(21.9)$ & $2.99 \times 10^{-7 * *}$ & $3.011(1.975-4.590)$ \\
& $76-80$ & $55(39.6)$ & $53(31.7)$ & 0.149 & $1.417(0.883-2.276)$ \\
& $>80$ & $26(38.2)$ & $37(25.9)$ & 0.073 & $1.772(0.948-3.314)$ \\
& & & & &
\end{tabular}

Notes: $* P<0.05 ; * * P<0.01$.

Abbreviations: $\mathrm{AAO}$, age at onset; $\mathrm{AD}$, Alzheimer's disease; $\mathrm{APOE}$, apolipoprotein $\mathrm{E}$ gene; $\mathrm{Cl}$, confidence interval; OR, odds ratio.

be due to the small frequency of $\varepsilon 2 \varepsilon 4$ genotypes or the coexistence of a "protective" and harmful effect in $\varepsilon 2$ allele and $\varepsilon 4$ allele, respectively.

In the present investigation, the $A P O E \varepsilon 2$ decreased the $\mathrm{AD}$ risks, and $\varepsilon 2 \varepsilon 3$ lowered the $\mathrm{AD}$ risk in total population, female, and LOAD subgroups. This effect is similar to those observed in other populations..$^{27,29}$ But the "protective" effect did not always show due to the lower frequency of $\varepsilon 2$ allele. ${ }^{7,30}$ In one study of north Chinese population, the $\varepsilon 2$ was indicated as a protective factor in male population, which was contrary to our result. This might be contributed to their small subject number and imbalanced sex distribution between $\mathrm{AD}$ and control groups. ${ }^{12}$

Researches indicated that the $\varepsilon 4$ allele took part in the pathogenesis of EOAD as well, ${ }^{29,31}$ and it was well replicated in our study. But a previous report in Chinese population did not find any association, which could be due to the small number of subjects. ${ }^{12}$ Some investigations indicated that $\varepsilon 4$ increased $\mathrm{AD}$ risk in women more than men, ${ }^{32,33}$ but others did not find the pattern. ${ }^{21,29}$ In a prospective study in Latin Americans, APOE $\varepsilon 4$ allele risk was significant only in women, ${ }^{32}$ but had a stronger effect in men from Sweden and Finland. ${ }^{27,34}$ In our population, APOE $\varepsilon 4$ increased AD risk in both sexes with a higher OR in the female group. The different results might be caused by ethnic origins.

$A P O E \varepsilon 2$ allele was reported not to affect $\mathrm{AAO}$ in $\mathrm{AD}$ patients in most studies. ${ }^{31}$ The differences of AAO between $\varepsilon 2 \varepsilon 2$ group and one or no $\varepsilon 2$ group did not reach significant, though the AAO of $\varepsilon 2 \varepsilon 2$ was 4 years later in number than that of one $\varepsilon 2$ group. This might be attributed to the very low frequencies of $\varepsilon 2 \varepsilon 2$ genotypes in $\mathrm{AD}$. APOE $\varepsilon 4$ allele was reported to lower the AAO of LOAD in a gene dosage way. The $\mathrm{AAO}$ of $\mathrm{AD}$ patients with $A P O E \varepsilon 4 \varepsilon 4$ genotype was 5-16 years lower than those with $\varepsilon 4$-negative ones. ${ }^{16}$ In our subjects, the AAO had a decrease of 2 years in patients of $\varepsilon 4 \varepsilon 4$ genotype in contrast to $\varepsilon 4$ carriers ( $\varepsilon 2 \varepsilon 4$ and $\varepsilon 3 \varepsilon 4$ ) or $\varepsilon 4$-negative ones, but not in a gene dosage way. Though we found some significant differences in $\mathrm{AAO}$ in the current study, we still could not deduce the effect of $A P O E$ genotype on the AAO with respect to the cross-sectional study. So further prospective studies should be implemented in Chinese Han population.

Whether $A P O E \& 2$ would reduce $\mathrm{AD}$ risk in a certain $\mathrm{AAO}$ range was controversial. ${ }^{27,35} \mathrm{We}$ found $\varepsilon 2$ 's protective role in the AAO of 61-65 and above 76. As for $\varepsilon 4$ haplotype, its $\mathrm{AD}$ risk decreased in people aged 70 years and above, ${ }^{36}$ which was quite similar to our results. There might be other genetic risk factors or environmental effects contributing to the AD onset in very old people.

This study had a few limitations. First, factors like diabetes, history of depression, stroke, and heart attack may also contribute to $\mathrm{AD}$ pathogenesis, but due to the incomplete information, we did not put those covariants into the binary logistic regression. Second, the subjects were recruited from memory disorders clinics but not the general population, which might exaggerate the impact of $A P O E \varepsilon 4$ on AD risks. In the population-based studies, the positive predictive value was lower, and hence $A P O E \varepsilon 4$ is not recommended for a screen test for AD. ${ }^{22,34}$

In conclusion, the $A P O E \varepsilon 4$ allele is a strong risk factor in $\mathrm{AD}$ in the Chinese Han population and it affects $\mathrm{AD}$ risk in a gene dosage effect, similar to those in other populations. The risk of $A P O E \varepsilon 3 \varepsilon 4$ toward $\mathrm{AD}$ was relatively smaller and the $A P O E \varepsilon 4 \varepsilon 4$ genotype lowered the $\mathrm{AAO}$ of $\mathrm{AD}$ in the 
LOAD group, which might be the specific characteristics of $A P O E$ polymorphisms in the Chinese Han population. The role of $A P O E$ protein in $\mathrm{AD}$ pathogenesis and other loci that will help to increase the AD-predictive value combined with $A P O E \& 4$ should be studied in the future.

\section{Acknowledgments}

The authors thank the participants of this study for their cooperation. This work was supported by a grant from the National Natural Science Foundation of China to Yi-Min Sun (81401048).

\section{Author contributions}

Ping $\mathrm{Wu}$ was responsible for data collection, data analysis, and manuscript drafting. Yi-Min Sun was responsible for study design, data analysis, data interpretation, and editing the manuscript. Hong-Lei Li, Zhi-Jun Liu, Qing-Qing Tao, Miao Xu, Qi-Hao Guo, and Zhen Hong were responsible for study implementation and data collection. All authors contributed equally to revising the manuscript and have approved the final version.

\section{Disclosure}

The authors report no conflicts of interest in this work.

\section{References}

1. Strittmatter WJ, Saunders AM, Schmechel D, et al. Apolipoprotein E: high-avidity binding to beta-amyloid and increased frequency of type 4 allele in late-onset familial Alzheimer disease. Proc Natl Acad Sci U S A. 1993;90:1977-1981.

2. Saunders AM, Strittmatter WJ, Schmechel D, et al. Association of apolipoprotein E allele epsilon 4 with late-onset familial and sporadic Alzheimer's disease. Neurology. 1993;43:1467-1472.

3. Bertram L, McQueen MB, Mullin K, Blacker D, Tanzi RE. Systematic meta-analyses of Alzheimer disease genetic association studies: the AlzGene database. Nat Genet. 2007;39:17-23.

4. Harold D, Abraham R, Hollingworth P, et al. Genome-wide association study identifies variants at CLU and PICALM associated with Alzheimer's disease. Nat Genet. 2009;41:1088-1093.

5. Naj AC, Beecham GW, Martin ER, et al. Dementia revealed: novel chromosome 6 locus for late-onset Alzheimer disease provides genetic evidence for folate-pathway abnormalities. PLoS Genet. 2010;6:e1001130.

6. Katzman R, Zhang MY, Chen PJ, et al. Effects of apolipoprotein E on dementia and aging in the Shanghai Survey of Dementia. Neurology. 1997;49:779-785.

7. Sando SB, Melquist S, Cannon A, et al. APOE epsilon 4 lowers age at onset and is a high risk factor for Alzheimer's disease; a case control study from central Norway. BMC Neurol. 2008;8:9.

8. Fei M, Jianhua W. Apolipoprotein epsilon4-allele as a significant risk factor for conversion from mild cognitive impairment to Alzheimer's disease: a meta-analysis of prospective studies. J Mol Neurosci. 2013;50:257-263.

9. Bonner-Jackson A, Okonkwo O, Tremont G. Apolipoprotein E epsilon2 and functional decline in amnestic mild cognitive impairment and Alzheimer disease. Am J Geriatr Psychiatry. 2012;20:584-593.
10. Zhou X, Miao H, Rausch WD, et al. Association between apolipoprotein E gene polymorphism and Alzheimer's disease in Uighur and Han populations. Psychogeriatrics. 2012;12:83-87.

11. Lai S, Chen Y, Wen Z. Association between apolipoprotein E polymorphism and Alzheimer's disease: a population-based study in Guangzhou, China. Zhonghua Liu Xing Bing Xue Za Zhi. 2001;22:202-204.

12. Chen D, Zhang JW, Zhang ZX, et al. [Apolipoprotein E gene polymorphisms and Alzheimer disease]. Yi Chuan Xue Bao. 2003;30:1167-1170.

13. Liu G, Zhang L, Feng R, et al. Lack of association between PICALM rs3851179 polymorphism and Alzheimer's disease in Chinese population and APOE epsilon4-negative subgroup. Neurobiol Aging. 2013;34:1310-1319.

14. Sun YM, Li HL, Guo QH, et al. The polymorphism of the ATP-binding cassette transporter 1 gene modulates Alzheimer disease risk in Chinese Han ethnic population. Am J Geriatr Psychiatry. 2012;20:603-611.

15. Donohoe GG, Salomaki A, Lehtimaki T, Pulkki K, Kairisto V. Rapid identification of apolipoprotein $\mathrm{E}$ genotypes by multiplex amplification refractory mutation system PCR and capillary gel electrophoresis. Clin Chem. 1999;45:143-146.

16. Corder EH, Saunders AM, Strittmatter WJ, et al. Gene dose of apolipoprotein E type 4 allele and the risk of Alzheimer's disease in late onset families. Science. 1993;261:921-923.

17. Poduslo SE, Huang R, Huang J, Smith S. Genome screen of late-onset Alzheimer's extended pedigrees identifies TRPC4AP by haplotype analysis. Am J Med Genet B Neuropsychiatr Genet. 2009;150B:50-55.

18. Evans DA, Bennett DA, Wilson RS, et al. Incidence of Alzheimer disease in a biracial urban community: relation to apolipoprotein $\mathrm{E}$ allele status. Arch Neurol. 2003;60:185-189.

19. Tang MX, Maestre G, Tsai WY, et al. Relative risk of Alzheimer disease and age-at-onset distributions, based on APOE genotypes among elderly African Americans, Caucasians, and Hispanics in New York City. Am J Hum Genet. 1996;58:574-584.

20. Irie F, Fitzpatrick AL, Lopez OL, et al. Enhanced risk for Alzheimer disease in persons with type 2 diabetes and APOE epsilon4: the cardiovascular health study cognition study. Arch Neurol. 2008;65:89-93.

21. Murrell JR, Price B, Lane KA, et al. Association of apolipoprotein E genotype and Alzheimer disease in African Americans. Arch Neurol. 2006;63:431-434.

22. Myers RH, Schaefer EJ, Wilson PW, et al. Apolipoprotein E epsilon4 association with dementia in a population-based study: the Framingham study. Neurology. 1996;46:673-677.

23. Fabian VA, Jones TM, Wilton SD, et al. Alzheimer's disease and apolipoprotein E genotype in Western Australia: an autopsy-verified series. Med J Aust. 1996;165:77-80.

24. Yu JT, Tan L, Hardy J. Apolipoprotein E in Alzheimer's disease: an update. Annu Rev Neurosci. 2014;37:79-100.

25. Raygani AV, Zahrai M, Raygani AV, et al. Association between apolipoprotein E polymorphism and Alzheimer disease in Tehran, Iran. Neurosci Lett. 2005;375:1-6.

26. Bahia VS, Kok F, Marie SN, et al. Polymorphisms of APOE and LRP genes in Brazilian individuals with Alzheimer disease. Alzheimer Dis Assoc Disord. 2008;22:61-65.

27. Qiu C, Kivipelto M, Aguero-Torres H, Winblad B, Fratiglioni L. Risk and protective effects of the APOE gene towards Alzheimer's disease in the Kungsholmen project: variation by age and sex. JNeurol Neurosurg Psychiatry. 2004;75:828-833.

28. Kardaun JW, White L, Resnick HE, et al. Genotypes and phenotypes for apolipoprotein E and Alzheimer disease in the Honolulu-Asia aging study. Clin Chem. 2000;46:1548-1554.

29. Bickeboller H, Campion D, Brice A, et al. Apolipoprotein E and Alzheimer disease: genotype-specific risks by age and sex. Am J Hum Genet. 1997;60:439-446.

30. Ganguli M, Chandra V, Kamboh MI, et al. Apolipoprotein E polymorphism and Alzheimer disease: the Indo-US Cross-national dementia study. Arch Neurol. 2000;57:824-830. 
31. Davidson Y, Gibbons L, Pritchard A, et al. Apolipoprotein E epsilon4 allele frequency and age at onset of Alzheimer's disease. Dement Geriatr Cogn Disord. 2007;23:60-66.

32. Molero AE, Pino-Ramirez G, Maestre GE. Modulation by age and gender of risk for Alzheimer's disease and vascular dementia associated with the apolipoprotein E-epsilon4 allele in Latin Americans: findings from the Maracaibo Aging Study. Neurosci Lett. 2001;307:5-8.

33. Payami H, Montee KR, Kaye JA, et al. Alzheimer's disease, apolipoprotein E4, and gender. JAMA. 1994;271:1316-1317.
34. Anttila T, Helkala EL, Kivipelto M, et al. Midlife income, occupation, APOE status, and dementia: a population-based study. Neurology. 2002; 59:887-893.

35. Slooter AJ, Cruts M, Kalmijn S, et al. Risk estimates of dementia by apolipoprotein E genotypes from a population-based incidence study: the Rotterdam study. Arch Neurol. 1998;55(7):964-968.

36. Miech RA, Breitner JC, Zandi PP, et al. Incidence of AD may decline in the early 90s for men, later for women: the Cache County study. Neurology. 2002;58(2):209-218. 


\section{Supplementary material}

Table SI Hardy-Weinberg equilibrium of APOE in AD patients and controls

\begin{tabular}{lllll}
\hline APOE & AD (actual) & AD (expected) & Controls (actual) & Controls (expected) \\
\hline Number & $875(\%)$ & & $1,195(\%)$ & $9(0.8)$ \\
$\varepsilon 2 \varepsilon 2$ & $4(0.5)$ & $2(0.2)$ & $7(0.6) 1.0$ & $158(13.2)$ \\
$\varepsilon 2 \varepsilon 3$ & $54(6.2)$ & $57(6.5)$ & $147(12.3)$ & $27(2.3)$ \\
$\varepsilon 2 \varepsilon 4$ & $22(2.5)$ & $22(2.5)$ & $41(3.4)$ & $728(60.9)$ \\
$\varepsilon 3 \varepsilon 3$ & $424(48.5)$ & $406(46.5)$ & $728(60.9)$ & $251(21.0)$ \\
$\varepsilon 3 \varepsilon 4$ & $289(33.0)$ & $322(36.9)$ & $263(22.0)$ & $22(1.8)$ \\
$\varepsilon 4 \varepsilon 4$ & $82(9.4)$ & $64(7.3)$ & $9(0.8)$ & \\
$\varepsilon 2$ & $84(4.8)$ & & $202(8.5)$ & $1,866(78.1)$ \\
$\varepsilon 3$ & $1,191(68.1)$ & & $322(13.5)$ & \\
$\varepsilon 4$ & $475(27.1)$ & & $9.261(0.099)$ & \\
$\varepsilon 2(P)$ & $5.137(0.399)$ & & \\
\hline
\end{tabular}

Abbreviations: AD, Alzheimer's disease; $A P O E$, apolipoprotein $E$ gene.

\section{Publish your work in this journal}

Clinical Interventions in Aging is an international, peer-reviewed journal focusing on evidence-based reports on the value or lack thereof of treatments intended to prevent or delay the onset of maladaptive correlates of aging in human beings. This journal is indexed on PubMed Central, MedLine,
CAS, Scopus and the Elsevier Bibliographic databases. The manuscript management system is completely online and includes a very quick and fair peer-review system, which is all easy to use. Visit http://www.dovepress. com/testimonials.php to read real quotes from published authors. 